\title{
Simultaneous Optical Recording of Activity from Many Neurons During Feeding in Navanax
}

\author{
Jill A. London, Dejan Zečević, a and Lawrence B. Cohen \\ Department of Physiology, Yale University School of Medicine, New Haven, Connecticut 06510, and The Marine Biological \\ Laboratory, Woods Hole, Massachusetts 02543
}

\begin{abstract}
Optical methods for monitoring changes in membrane potential have been used to measure action potential activity in the buccal ganglion of an oplsthobranch mollusc, Navanax inermis, while the animal was feeding. During feeding activity was detected in $10-15 \%$ of the approximately 200 neurons present in the ganglion. Control experiments carried out to determine the completeness of the optical recording showed that activity in at least $70 \%$ of the neurons could be detected. Thus, in certain invertebrate ganglia, it is possible to make a reasonably complete recording of the neuron activity responsible for generating relatively complex behaviors.
\end{abstract}

A complete understanding of the neuronal interactions that underlie even simple invertebrate behaviors has been difficult to attain (Selverston, 1980). One reason for this difficulty is that present electrophysiological techniques can sample only a few of the many neurons likely to be involved. Often the publication of a model to explain the generation of a behavior is followed by the discovery of additional neurons that participate in the behavior. Optical methods for monitoring action potential activity were developed (Salzberg et al., 1973, 1977; Grinvald et al., 1981; Boyle et al., 1983) with the aim of being able to monitor all of the spike activity in simpler invertebrate ganglia. This technique is based on the finding that the optical properties (absorption, fluorescence, and/or birefringence) of membranes stained with certain dyes change when membrane potential changes (reviews by Cohen and Salzberg, 1978; Waggoner, 1979; Salzberg, 1983; Grinvald, 1985). In this paper we report substantial progress in 3 areas. First, we show that we can simultaneously record the activity of at least $70 \%$ of the neurons in the buccal ganglion of the marine mollusc, Navanax inermis, a ganglion that contains about 200 neurons. Second, we have made such recordings in a minimally dissected preparation where we simultaneously monitored the feeding behavior that is gen-

\footnotetext{
Received Feb. 18, 1986; revised Aug. 25, 1986; accepted Aug. 26, 1986.

Eduardo Macagno kindly allowed us to use the CARTos system in his laboratory for counting the number of cell bodies present in methylene blue-stained ganglia. We thank Sarah Lesher for assistance with the programming. We are grateful to M. V. L. Bennett for pointing out the importance of the light-scattering measurement and to Amiram Grinvald for pointing out that it was important to determine $I / I_{0}$ at the central detector in this measurement. We thank A. Grinvald for suggesting the use of the oxonol, RH155, and we thank R. Hildesheim and A. Grinvald for providing this and several additional dyes. Supported by NIH Grant NS08437, Fulbright Grant 83-04765 to D.Z., and a Grass Foundation Fellowship to J.A.L.

a Present address: Institute for Biological Research, 29 November 142, 11000 Belgrade, Yugoslavia.

Copyright (C) 1987 Society for Neuroscience $0270-6474 / 87 / 030649-13 \$ 02.00 / 0$
}

erated by the ganglion. Finally, we found that a voltage-sensitive oxonol dye, RH1 55 (Grinvald et al., 1980), has relatively large signals with minimal pharmacologic effects, no detectable photodynamic damage, and very slow bleaching in the Navanax preparation. Thus, we can now record much of the action potential activity in a minimally dissected preparation for a long period of time. Preliminary reports of these experiments have been presented and the methods demonstrated to the Society of General Physiologists (London et al., 1984, 1985; Zecević et al., 1985).

The feeding behavior of Navanax has been described and analyzed by cinematography (Paine, 1963; Murray and Lewis, 1974; Woollacott, 1974; Leonard and Lukowiak, 1984; Susswein et al., 1984). Navanax find their prey, usually other opisthobranch molluscs, by following mucous trails. When the prey is contacted, the pharynx is protracted to form a seal on the prey. The protraction is followed by a vigorous expansion of the pharynx, called either an expansion (Susswein et al., 1984) or a strike (Leonard and Lukowiak, 1984) that sucks the prey into the pharynx. Peristaltic contractions of the pharyngeal muscles then push the food into the esophagus. We describe experiments directed at detecting the neuronal activity that occurs during and immediately following the expansion. While much of the neuronal circuitry controlling the pharyngeal musculature has been shown to be located in the buccal ganglion (Woollacott, 1974; Spira et al., 1980; Spray et al., 1980a, b), we do not know of reports of recordings from buccal neurons during actual feeding.

\section{Materials and Methods}

Figure 1 illustrates the whole animal preparation and apparatus we used to measure absorption changes from buccal ganglia during feeding activity. Navanax (20-160 gm) were positioned in a seawater-filled chamber, ventral side up. A slit was made in the ventral body wall to allow the microscope objective to view the buccal ganglia. The ganglion was illuminated by light from a $12 \mathrm{~V}, 100 \mathrm{~W}$ tungsten filament lamp. The lamp output was heat-filtered and then passed through an interference filter (usually $705 \pm 25 \mathrm{~nm}$ for RH155), chosen because it gave the largest signal-to-noise ratio. The light from the microscope condenser was transmitted to the ganglion via a 1-mm-diameter clad quartz rod. A 0.6 n.a. condenser was used; to obtain the maximum intensity, the luminous field diaphragm (Piller, 1977) was adjusted so that the diameter of the illuminating spot was approximately equal to the diameter of the light-guide. The light intensity reaching the photodetectors with the light-guide was similar to that obtained using ordinary Kohler illumination on isolated ganglia. The light-guide was encased in stainless steel tubing to provide mechanical strength. The ganglia were not desheathed. The light-guide was passed through an inverted animal, via a slit in the ventral pharynx and holes in the dorsal pharynx and dorsal body wall; the light-guide was then clamped to the bottom of the chamber (not shown). (One end of the tube was surrounded by Sylgard to 

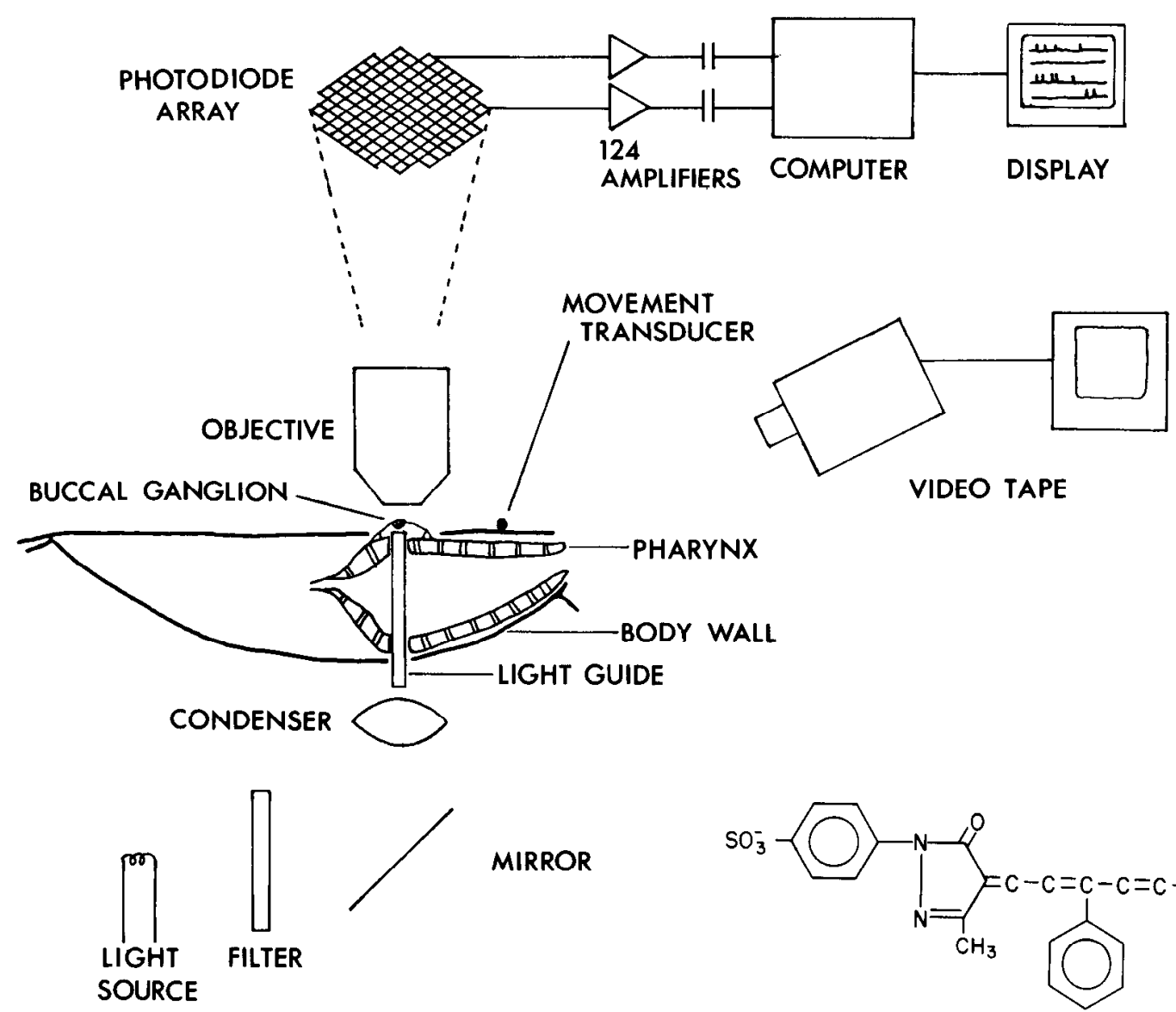

MIRROR<smiles>CC1=NN(c2ccc(S(C)(=O)=O)cc2)C(=O)C1=CC=C(C#Cc1c(C)nn(-c2ccc(S(C)(=O)=O)cc2)c1[O-])c1ccccc1</smiles>

RH155, Oxonol

Figure 1. Schematic diagram of the apparatus and preparation. A real, inverted, magnified image of the ganglion was formcd on 124 elements of a $12 \times 12$ silicon photodiode array (MD 144-5PV, Centronic Ltd., Croydon, UK) by a Leitz 32×, 0.6 n.a. objective (measured magnification, $31 \times$ ). Each element of the array is $1.4 \times 1.4 \mathrm{~mm}$. The output of each of the photodiodes was followed by an amplifier, and the amplified signals were stored in a digital computer. The output of each detector in the diode array was amplified twice (LF356N: National Semiconductor, Inc.). The high-frequency response of the amplifiers was limited in 2 stages; the first had a 1 msec time constant and the second a 0.5 msec time constant. The 2 amplifiers were DC coupled for measuring the resting light level (used to calculate $\Delta I / I_{r}$ ) and were capacity coupled during the measurements of spike activity. The capacity coupling reduced the low-frequency noise from vibrations, drifts due to apparatus instability, and movements of the ganglion. Because the signals are small relative to the resting light intensity and because the intensity reaching adjacent detectors often varied by $50 \%$, the measurements are susceptible to interference from movement. An analog capacity coupling time constant of either 25 or 100 msec was needed to keep the output of the second amplifier from saturating during movement artifacts. While this amount of filtering does not dramatically affect the size or shape of an action potential recording, the disadvantage of such a fast coupling time constant is that it will severely attenuate slow signals such as synaptic potentials. (Amplifier sets can be obtained from V. Pantani, 432 Union Avenue, West Haven, CT 06516.) The amplifier outputs were digitized and recorded every $0.85 \mathrm{msec}$. A $17 \mathrm{sec}$ recording, from 128 channels, had $2.56 \mathrm{M}$ bytes of data. In addition to the analog filtering, the high- and low-frequency noise was further reduced by digital filtering. The high-frequency filtering was implemented by use of a 1-2-1 smoothing routine. The central data point was multiplied by 2 , the adjacent data values were added to it, the sum was divided by 4 , and the central point was replaced by this result. Two passes with this filter were used for the results illustrated in Figure 4 . The low-frequency filtering algorithm we used computed the value of the next data point by adding the difference between the next point and the present point to a fraction of the present point. When this fraction was $7 / 8$, the coupling time constant was approximately $15 \mathrm{msec}$. The results shown in Figures 3 and $4 A$ were obtained using this fraction. For analysis, the outputs of the individual detectors were displayed, using digital-to-analog converters, on either a Tektronix 4012 terminal equipped with an analog-multiplexer card or a Tektronix 4633 continuous paper copier. At the paper speed we used, the 17 sec recording was about $2 \mathrm{~m}$ long. The programs, assembly language subroutines called by FORTRAN, are available from the authors. The apparatus is a modification of equipment described previously (Salzberg et al., 1977; Grinvald et al., 1981). A more detailed discussion of the methods has appeared elsewhere (Cohen and Lesher, 1986).

which the ventral pharynx was pinned. The muscles of the pharynx were pinned to the perimeter of the Sylgard in such a way that the buccal ganglion was positioned over the light-guide.) The animal's movements were restricted since the pharynx could no longer move relative to the body wall, and the passage to the esophagus was partially blocked by the light-guide. Most preparations made repeated pharyngeal expansions in the absence of food stimuli. Such spontaneous expansions are not seen in field observations (Leonard and Lukowiak, 1984) but were seen in the laboratory in an animal that had been cooled and then rewarmed but not dissected. In some preparations we observed foodinduced feeding. Food, pieces of the snail, Bulla gouldiana, were tied to a miniature fishing rod (no reel) and introduced into the chamber manually. The animal's behavior was recorded with a camera and videotape recorder and with a movement transducer placed on the ventral body wall over the pharynx.

At the time of these experiments, the largest optical signals in invertebrate ganglia came from measurements of absorption, although fluorescence (Salzberg et al., 1973; Grinvald et al., 1982) and birefringence (Boyle and Cohen, 1980) signals had also been measured. More recently, we measured fluorescence signals with signal-to-noise ratios nearly as large as absorption signals. However, with 2 of the styryl dyes (RH386 and RH725), the photodynamic damage and bleaching were substan- 
LIGHT SCATTERING, NAVANAX

\section{NO PREPARATION}

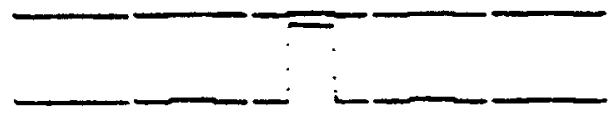

\section{WITH BUCCAL GANGLION}

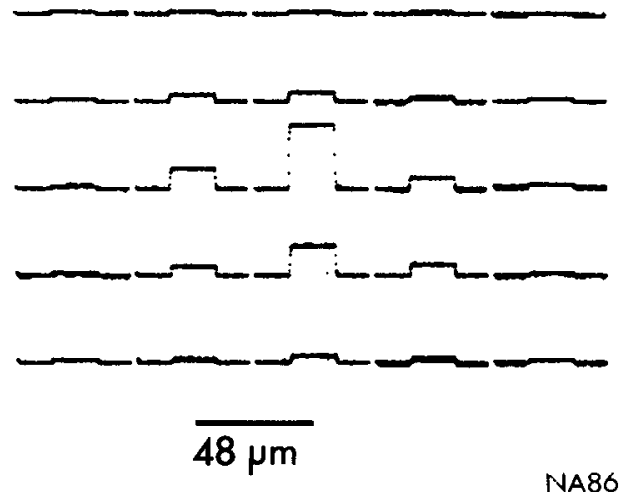

Figure 2. Effects of scattering on the distribution of light from a point source onto the array. Upper, A $35 \mu \mathrm{m}$ pinhole in aluminum foil in the chamber bottom was covered with saline and illuminated. The pinhole was in focus. More than $90 \%$ of the light fell on 1 detector. Lower, The pinhole was covered by a Navanax buccal ganglion. The light from the pinhole was spread over several detectors. A $32 \times, 0.6$ n.a. objective was used. Before the pinhole was placed in the object plane the optics were set up using Kohler illumination. The display gains were adjusted so that the largest signal in the 2 trials would be approximately the same size in the figure. Scattering in Navanax was substantially less than that previously measured in salamander olfactory bulb (Orbach and Cohen, 1983).

tially more rapid than with RH155. The results reported here are from measurements of absorption using ordinary bright-ficld light microscopy.

Buccal ganglia were stained for $30 \mathrm{~min}$ with a $0.5 \mathrm{mg} / \mathrm{ml}$ seawater solution of RH155. This dye can be purchased as NK3041 from Nippon Kankoh-Shikiso Kenkyusho Co. Ltd. (2-3 Shimoishii, 1-Chome, Okayama, Japan). Both the dissection and the staining took place at low temperature $\left(2 \pm 2^{\circ} \mathrm{C}\right)$. Following staining, the ganglion was rinsed and then covered with a $1-\mathrm{mm}$-thick layer of $3 \%$ agar; the agar had been boiled for $10 \mathrm{~min}$ and kept at $40^{\circ} \mathrm{C}$. When the agar hardened it fixed the position of the ganglion relative to pins inserted in the Sylgard. In the absence of the agar, the ganglion would shift completely out of the field of view during a pharyngeal expansion. Sometimes the agar reduced the movement so that it could no longer be detected visually with a dissecting microscope; however, large, slow movement artifacts were still present in the optical rccordings. Approximately 30-60 min elapsed between the end of the staining and the first recording; some experiments lasted another $4 \mathrm{hr}$. The bath temperature was $16 \pm 1^{\circ} \mathrm{C}$.

For counting the number of neuron cell bodies present, ganglia were stained overnight in a saturated solution of methylene blue. They were then fixed in formaldehyde, dehydrated in acetone, and cleared with methyl salicylate. The cell number and a histogram of cell size were obtained using CARTos, a computer-aided system (Macagno, 1980).

\section{Results}

Dye screening

Although we previously reported (Grinvald et al., 1981; Boyle et al., 1983) that a merocyanine dye would give relatively large signals from Navanax ganglia, additional experiments indicated that this result was not reliable; in some ganglia the staining appeared to be good but the signals were small. Accordingly, we tested 23 additional merocyanine and oxonol dyes. The pyrazo-oxonol dye, RH155 (Grinvald et al., 1980), whose structure is shown at the bottom right of Figure 1, and its diethyl and dipropyl derivatives, RH479 and RH482, gave relatively large signals that were reasonably reproducible from ganglion to ganglion.

In several experiments we cut the ganglion in half to cxaminc the dye penetration into the tissue. For the concentrations and staining periods used, several dyes, including RH155, did not visibly penetrate into the neuropil even though cell-body staining was easily detected by visual examination. Therefore, the signals described here must originate from cell bodies and not from dendritic or axonal processes in the neuropil.

\section{Pharmacologic and photodynamic effects of the dye}

Not only did the pyrazo-oxonal dye give a relatively large absorption signal, but pharmacologic and photodynamic effects were difficult to detect. To look for pharmacologic effects we examined the behavior of 3 control preparations in which staining was omitted. The control preparations exhibited the same kinds of behaviors as stained preparations, both spontaneous expansions and food-induced expansion followed by ingestion, and when they occurred, these behaviors were indistinguishable in stained and control animals. However, it is our impression that it was easier to elicit food-induced feeding behavior in control preparations. More systematic observations would be required to determine if a real difference existed. The absence of dye penetration into the neuropil may, in part, account for the absence of severe pharmacologic effects. There were also no detectable pharmacologic effects of the dye on the currents measured during voltage-clamp steps in squid axons (Grinvald et al., 1980; K. Kamino and L. B. Cohen, unpublished observations).

Neither dye bleaching nor photodynamic damage-damage resulting from illumination of a stained preparation in the presence of $\mathrm{O}_{2}$ (Pooler, 1972; Ross et al., 1977)-could be detected following the $17 \mathrm{sec}$ illumination periods normally used. In 1 experiment we inadvertently left the light on for $1600 \mathrm{sec}$. After this exposure the signal size was reduced by about $30 \%$; the bleaching appears to have a half-time of about $40 \mathrm{~min}$. The behavior of this animal, as indicated by the movement recordings during spontaneous expansions, did not appear to be affected by the illumination.

\section{Light scattering}

Light scattering by the ganglion will blur the images of cell bodies. In living Navanax ganglia, cell bodies on the bottom side (side away from the objective) cannot be distinguished by eye using ordinary light microscopy. If the scattering were very severe, then the light from a small spot (or small cell body) on the bottom side of the ganglion would reach many photodetectors. Such a result would cause difficulty in 2 ways. First, since the number of detectors on which a signal was seen was used as an indicator of cell body size (see below), scattering would 


\section{NEURON IDENTIFICATION}

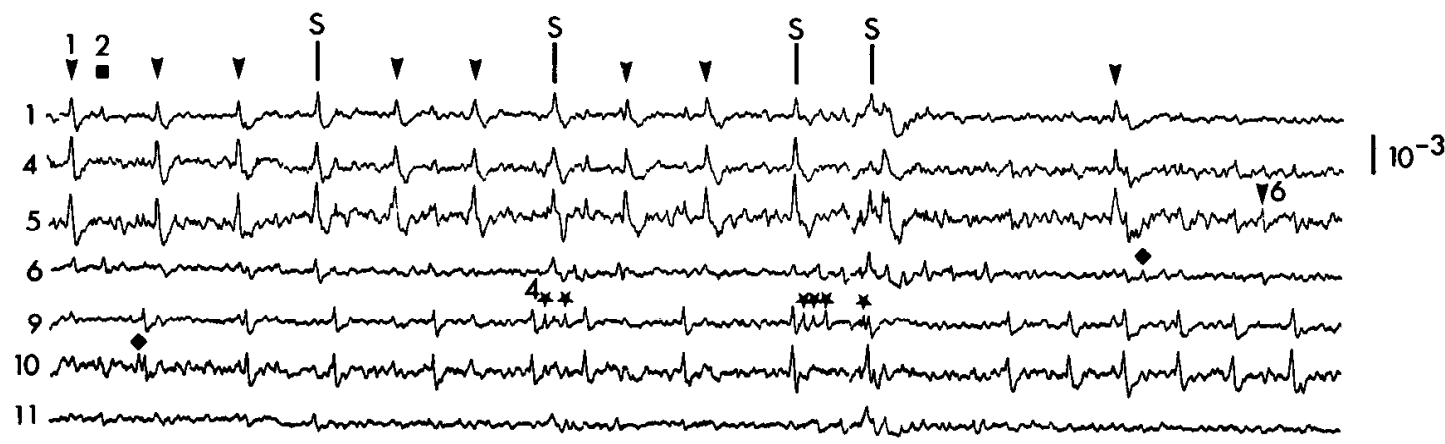

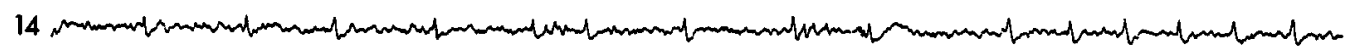

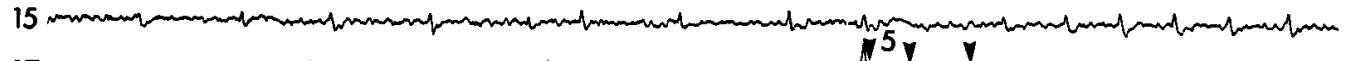

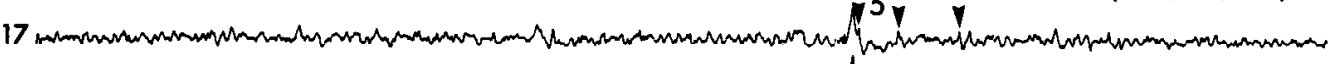

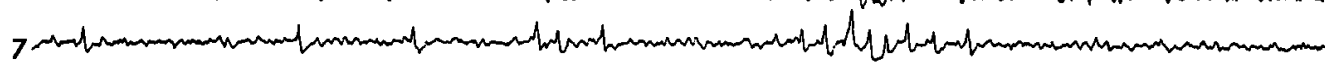

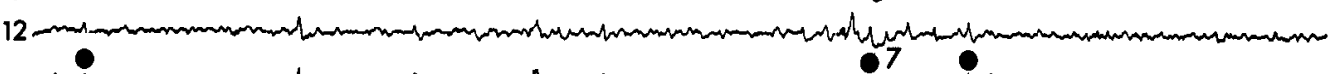

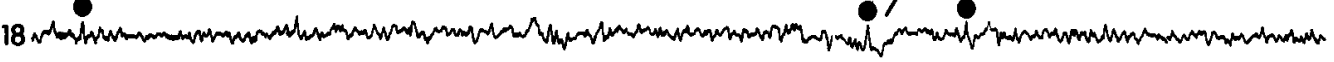

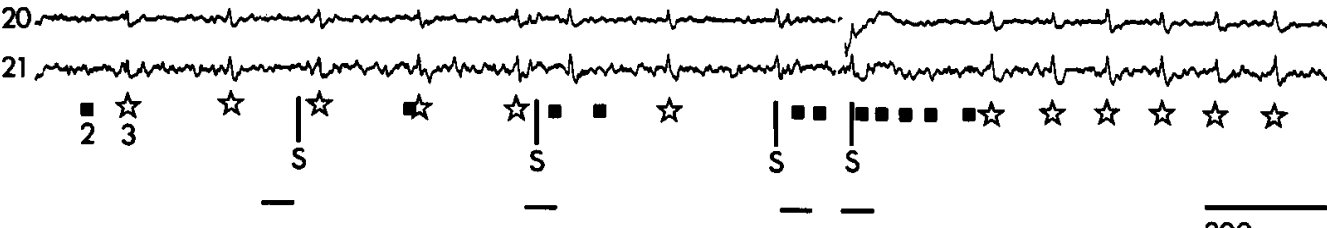
\begin{tabular}{|l|l|l|l|l|}
\hline & 18 & 12 & 7 & \\
\hline 17 & 11 & 6 & 1 \\
\hline 21 & 15 & 10 & 4 \\
\hline 20 & 14 & 9 & \multicolumn{1}{|c|}{} \\
\hline & & &
\end{tabular}

$200 \mathrm{msec}$

Figure 3. Optical recordings from 15 photodiodes. Our identification procedure indicates that much of the spike activity seen on these detectors results from relatively large neurons; light from these neurons will fall on several adjacent detectors; thus, identically timed signals will be seen on these adjacent detectors. The analysis indicated that activity of at least 8 neurons was needed to account for the signals seen in this figure. The numbers at left indicate the array element; a map of this portion of the array is shown at the lower left. Two detectors are labeled with the number 10. Because of a manufacturing flaw, the outputs of these 2 detectors were connected. This section of recording was selected because there are a relatively large number of neurons in a short, compact section and because it illustrates some difficulties in identifying the activity of individual neurons. The length of the vertical bar to the right of the trace from detector 4 indicates a change in intensity divided by the resting intensity, $I / I_{r}$, of $10^{-3}$. This calibration is approximate for other traces. This section of recording is from an experiment aimed at determining the maximum number of neurons whose activity could be detected (see Table 1). A nerve was stimulated 4 times with 50 msec pulses (horizontal bars) during the recording period illustrated; a section of the recording between the third and fourth stimulus is omitted. The first stimulus was the smallest, the fourth stimulus the largest. This large stimulus results in a stimulus artifact that can be seen on some detectors both at the beginning and the end of the pulse. The complete analysis of stimulation experiments, for all 124 photodiodes and all 6 stimulations, took approximately 50 person-hr (Lektin and Osmol, 1980).

lead to an overestimate of cell size. Second, since the light is spread over several detectors, the signal-to-noise ratios on each of the detectors would be smaller than on a single detector that received all the light. To obtain an indication of the scattering by Navanax buccal ganglia, we made a $35 \mu \mathrm{m}$ spot of light (705 $\mathrm{nm}$ ) at the object plane and imaged that spot on the array using the $32 \times$ objective. With this magnification, the image of the spot was $1.1 \mathrm{~mm}$ in diameter, slightly less than the size of a single element of the photodiode array. The spot was positioned so that almost all of the light fell on 1 detector. In Figure 2 (top), the intensity that reached each detector is indicated by the height of the stcp in each trace. The intensity that reached the central detector was more than 50 times larger than the mean of the intensity on the 4 abutting detectors. A Navanax buccal ganglion was then positioned over the spot and the measurement repeated. Because of scattering, more light fell on neighboring detectors (Fig. 2, bottom), but the central detector still received 3 times the intensity of the mean of the 4 abutting detectors. Thus, scattering will not lead to a severe distortion in the estimated size of the cell body. Moreover, the result in 
Figure 2 included the scattering from 2 thicknesses of connective tissue sheath, whereas light from cell bodies is scattered only by the upper sheath.

Even though the intensity reaching the central detector was 3 times larger than that reaching the neighboring elements, the light intensity on that central detector was only $27 \%$ of the total light reaching the 25 detectors (Fig. 2). When we compared the intensity reaching the central detector with and without the ganglion present, the presence of the ganglion reduced the intensity by about $90 \%$. Thus, in the present experiments, the signal-to-noise ratios are substantially reduced by light scattering. This degradation will be more severe for small neurons than for neurons whose image reaches several detectors.

\section{Interpreting photodetector outputs in terms of activity of individual neurons}

The interpretation of measurements made with a regular, 2-dimensional array must take into account the fact that the ganglion is an irregular, 3-dimensional preparation. First, activity in large neurons will lead to identically timed action potential signals on adjacent detectors (duplicate signals). With a $32 \times$ objective, each element of the array will receive light from a square area of the ganglion that is $45 \mu \mathrm{m}$ on a side. Since a number of cell bodies in the buccal ganglion have diameters that are much larger than $45 \mu \mathrm{m}$, the light from these cells will fall on several neighboring detectors. Second, most detectors in the array will receive light from more than 1 cell body (multicellular recording). Because both the top and bottom surfaces of the ganglion are closely packed with cell bodies, most detectors must receive light from at least 2 neurons. Observations on stained and cleared preparations used for cell counting showed that some light paths through the ganglion encounter as many as 4 cell bodies. Thus, the outputs of individual detectors can have signals from more than 1 neuron. Most often the sizes of the signals from the different neurons will be unequal. Furthermore, because cell bodies in different planes are unlikely to have exactly superimposed images, the signals from larger cell bodies will probably differ in their distribution on the photodiode elements.

Both duplicate signals and multicellular recordings are illustrated in Figure 3, in which the outputs of 16 photodetectors are plotted. The numbers at the left of each trace indicate the diode number; a map showing the relative positions of the diodes within the array is given below the tracings. Evidence from simultaneous optical and microelectrode measurements showing that signals like those in Figure 3 actually arise from action potentials was first presented by Salzberg et al. (1973) and subsequently confirmed many times (e.g., Salzberg et al., 1977; Ross and Reichardt, 1979; Grinvald et al., 1981; Ross and Krauthamer, 1984). The data in Figure 3 are from a section of a stimulation experiment (see below) in which a nerve was given four 50 msec stimuli (the 4 horizontal bars below the traces). We think that at least 8 individual neurons are needed to account for these data.

One example of duplicate signals is the train of spikes seen on several adjacent detectors at the end of the recording (detectors $9,10,14,15,20$, and 21). Occurrences of this group of spikes, which we interpret as the action potentials of a single relatively large neuron (first cell), are indicated by the open stars at the bottom. In each case we have checked that duplicate signals are found on neighboring detectors before they are as- signed to a single neuron. An example of a multicellular recording, with 2 action potentials on 1 detector is the first 2 spikes seen on detector 1 ; the first spike is much larger than the second. In addition, Figure 3 also illustrates one difficulty in the analysis; an example is the interpretation of the small spike signals seen on detector 5 at the arrow labeled 6 near the end of the recording. At the other occurrences of this small spike there were the simultaneous signals (open stars). But the spike at arrow 6 occurs alone and must therefore represent an action potential in a small neuron. The interpretation of the other instances of similar small signals on detector 5 is ambiguous. They could represent activity in this small cell, which happened to be electrically coupled to the large neuron, or they could just be small signals resulting from the fact that detector 5 sees the edge of the large cell. However, even though the assignment of the small spikes on trace 5 is ambiguous, it is necessary to assume that there are 2 active neurons to account for the signal at arrow 6 (second cell). This kind of ambiguity would occur most often in ganglia, which, as in Navanax, have substantial electrical coupling between neurons (Levitan et al., 1970; Spira and Bennett, 1972; Spira et al., 1980). The ambiguity seems unresolvable without additional data. The analysis of the signals in Figure 3 is continued in the small print section which follows.

At arrowhead 1 at the top there are identically timed spikes on detectors 1,4 , and 5 ; these are often accompanied by small signals on detector 6 (third cell). Detector 1 has additional, smaller signals that are not accompanied by spikes on 4, 5, and 6 . One of these smaller signals on detector 1 is seen at square 2 . This signal is accompanied by spikes on detectors $6,7,12$, and 18 , and this constellation is seen 10 more times at the squares on the bottom (fourth cell). There is, however, a puzzling aspect to this identification. The signals on detectors that appear to be at the edge of neurons, in this case detector 1 , are quite variable. There is a clear signal on detector 1 on the first occurrence of the second cell spike, but it is difficult to detect on the third occurrence. This kind of result could be due to an inadequate signal-to-noise ratio or to a slight movement of the ganglion, which would have a disproportionately large effect on signals from detectors that see only an edge of the cell body. A fifth active neuron is identified by action potentials, most easily detected on trace 9 (solid stars), that occur just after the second, third, and fourth stimulations. Simultaneous signals are also seen on detector 14 and sometimes on 20 . There are 3 small signals at the 3 arrowheads on trace 17 (sixth cell).

The 3 filled circles on the trace from detector 18 indicate spikes that occur simultaneously with spikes at the filled squares, the second cell. In many other instances of the second cell's spikes there is no signal on detector 18 , which is especially clear in the record between the second and third filled circles. We interpret the events at the circles to represent simultaneous firing of the second cell and a smaller adjacent cell seen most clearly on detector 18 (seventh cell).

There are 4 instances of simultaneous signals on many detectors (lines labeled with the letter S). Simultaneous signals are often seen during or following nerve stimulation. The signals at the first and second $\mathrm{S}$ can most easily be interpreted as the sum of first and second cells (top arrows and filled squares). The signals at the third $\mathrm{S}$ are more complex. These signals could in part represent simultaneous firing of the first and third cells (top arrows and stars). Then the small signals on detectors 7 and 12 , detectors that had large signals from the second cell (squares), could represent the results of electrical coupling between the first and third cells and the second cell. With this interpretation we do not need to assume that an additional cell was active. The signals at the fourth $S$ occur during a large stimulus. In this case there are action potentiallike signals on every detector but 18 . Since the signals on detectors 17 , 7 , and 12 are larger than any others on these detectors, we presume that this extra signal size must represent the activity of at least 1 additional neuron (eighth cell). Thus, if many cells fire simultaneously after a stimulus, we cannot tell how many neurons are responsible for the signal. This difficulty will lead to an underestimation of the number of active neurons if the neurons do not fire independently at other times in the recordings. 


\section{AVERAGED FROM 16 SPIKES}
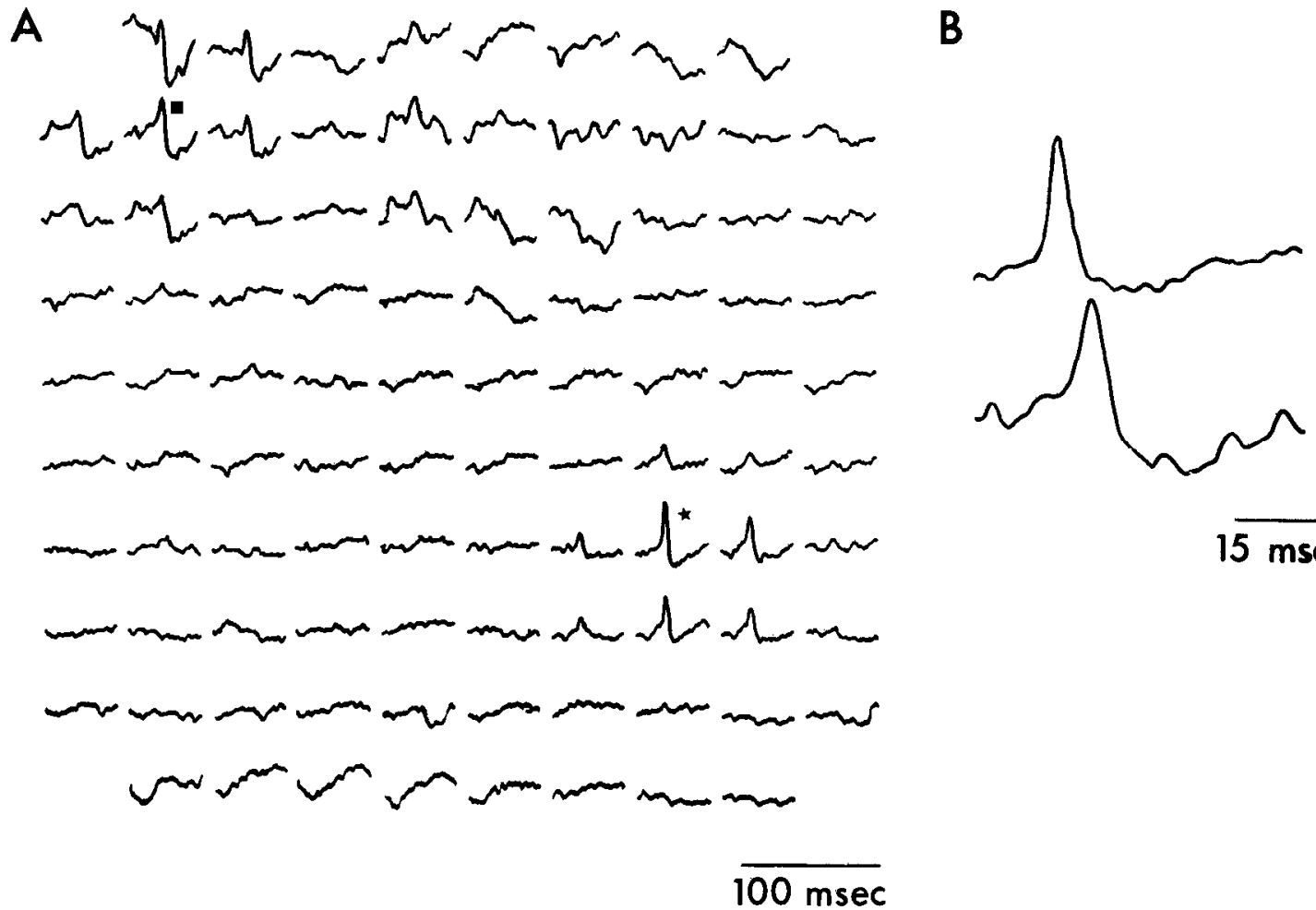

$15 \mathrm{msec}$

NA8601

Figure 4. Results of spike-triggered signal averaging using the times of 16 of the action potentials seen on detector 18 (star) in the recording shown in Figure 8 as the trigger for the averaging program. $A$, Traces arranged according to the disposition of the detectors on the array; the outputs of 96 of the 124 elements are shown. Several detectors that are neighbors of detector 18 have identically timed signals with the same shape; presumably this group of signals is from 1 neuron. This kind of display thus provides a second method for determining the number of detectors on which the signal from an individual neuron is found. The number of detectors is dependent on the relative size of the noise in the measurement and on the relative signal size that is accepted as representing the cell. Since light scattering will cause the light from the cell to spread to areas of the image plane that would not otherwise receive light from the cell, with a very large signal-to-noise ratio the signal from each cell would be detectable on every photodiode. In the upper left corner a second group of spikes is seen (less clearly). This activity is delayed by 7 msec compared to the spikes in cell 18. $B$, Outputs of detectors 18 (star) and 115 (square) are shown on an expanded time base. The results for this figure were taken from the data used for generating Figure 8 . The digital low-frequency filter was used for the results presented in $A$ but not used for the results in $B$.

There are a number of instances where the signal-to-noise ratio is insufficient to be sure that there is a signal. Two examples are at the diamonds on detector 6 and 10. Doubtful signals have been ignored in the analysis.

The data illustrated in Figure 3 are from a stimulation experiment (see below), where we attempted to activate a large fraction of the neurons in the ganglion. The analysis of the optical signals obtained during spontaneous expansions and feeding (Figs. 5, 7, and 8) was easier because fewer neurons were active. Once all of the individual action potentials were assigned to neurons, the times of each spike were entered into the computer. Where the signal-to-noise ratio was large and the activity of only 1 cell appeared on the detector, a computer program automatically found the action potentials and entered the peak times. In less favorable cases, the indentification process required operator intervention.

\section{Spike-triggered averaging}

One method of determining the detectors on which a signal is seen is simply to look at data like that shown in Figure 3 and list the detectors. A second method involves an averaging program that uses the time of occurrence of action potentials in an individual neuron to trigger the averaging. Triggering the average from the spike times will improve the signal-to-noise ratio and allow a more accurate determination of the shape of the signal on the detector used for entering the spike times. More importantly, the signals from the same cell that appear on adjacent detectors will also be averaged. A time, $35 \mathrm{msec}$ before the peak of each spike from a neuron, was used as the starting time for the averaging program. This program averages the data from each of the 124 detectors. An example of the results of the averaging program is illustrated in Figure $4 A$. The outputs of each detector are displayed as they are arranged on the array. Detector 18, whose output was used for entering the spike times of this cell, is indicated by a star. There are clear action potential signals on detector 18 and several neighbors. Since the effect of light scattering and out-of-focus cells (see above) will cause the signal to spread by an unknown amount, in subsequent figures we determined the location and size of a neuron by including the detectors with signals that were at least $50 \%$ of the largest signal.

\section{Spontaneous expansions}

The spike times for each identified neuron were also used to generate raster diagrams. A raster diagram of the action poten- 


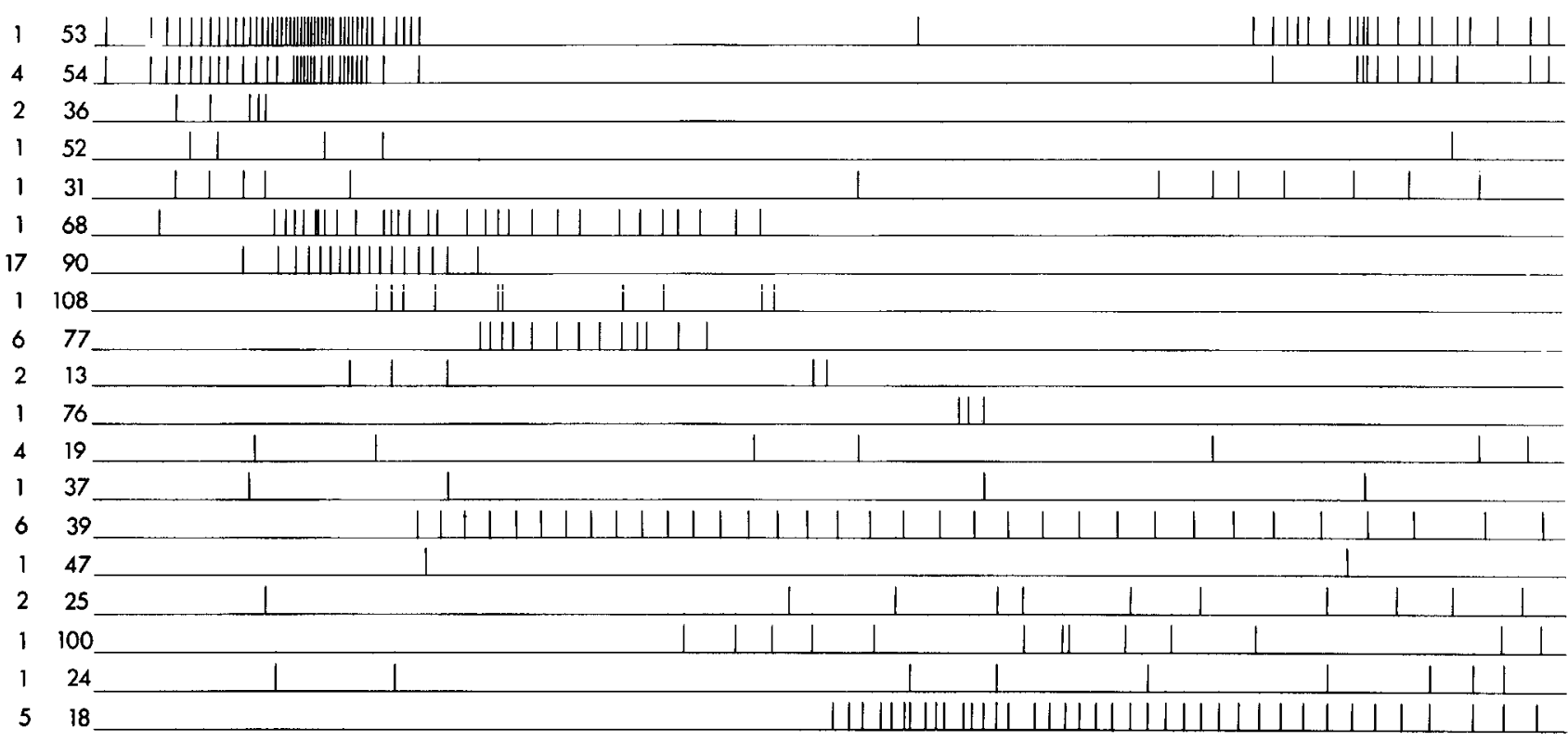

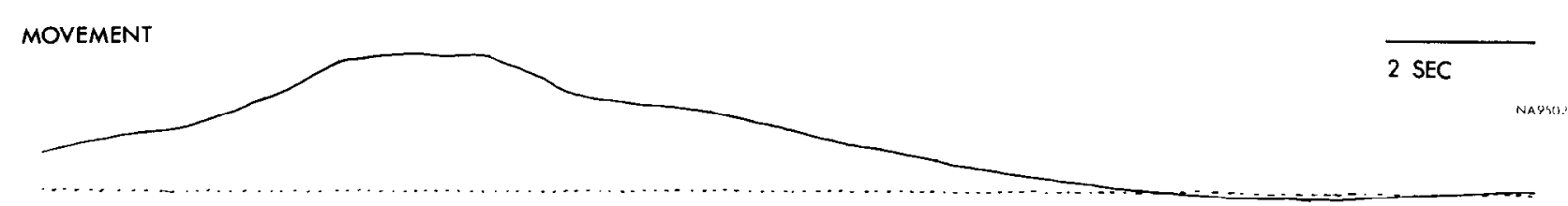

Figure 5. Raster diagram of the action potential activity from 19 neurons during a spontaneous expansion. The bottom trace is a recording from the tension transducer; in this and subsequent figures, upwards indicates a pharyngeal expansion. The numbers just to the left of each trace indicate the photodiode output used for entering the spike times into the computer; the numbers at far left indicate the number of photodiodes on which that action potential activity was detected. The activity illustrated as number 90 was seen on 17 adjacent detectors; this is a very large neuron. Activity of other neurons that appear on only 1 diode presumably represent small neurons. This preparation was also used for the photographic analysis illustrated in Figure 6; it is the third preparation listed in Table 1.

tials recorded optically from a buccal ganglion during a spontaneous pharyngeal expansion is shown in the top 19 traces of Figure 5. Each vertical line in a trace represents 1 action potential. The number immediately to the left of each trace indicates the detector used for entering the time of the action potentials into the computer; this number will be used to name cells. The second column of numbers, further to the left, gives the number of detectors on which the signal was seen, indicating cell size. The trace at the bottom of Figure 5 is the recording from the movement detector placed on the body wall over the pharynx. An upward displacement indicates expansion. Most of the spike activity shown in Figure 5 is related to the expansion of the pharynx; measurements made during inactive periods had much less spike activity.

The activity of cell 36 , which occurred early in the expansion, was seen on 2 adjacent detectors. Cell 90 , which generated action potentials during most of the expansion phase, had activity on 17 neighboring detcctors. Cell 39 made a long train of action potentials starting at the peak of the expansion and lasting the duration of the recording; this train was seen on 6 detectors. Cell 18 made a train of action potentials starting in the middle of the contraction phase. This activity was seen on 5 detectors. A number of cells had activity that was seen on only a single detector. There were 2 instances where individual neurons (as we have identified them) fired simultaneously. This occurred often with cells 53 and 54 and less often with cells 24 and 18.
Spira et al. (1980) have previously observed simultaneous firing of motor neurons in isolated ganglia.

\section{Cell body identification}

To correlate the spike activity illustrated in Figure 5 with cell bodies in the ganglion, photographs of this ganglion were compared with the location of recorded spike activity on the diode array. Following the optical recording we replaced the diode array with a camera back whose film was in the plane that the array had occupied. A photograph, made with the objective focused on the upper, ventral surface of the ganglion, which has mainly large cell bodies, is shown in Figure 6A. An alignment procedure, which had an accuracy of about $1 / 2$ of a pixel, was used to allow a superimposition of the outline of the diode array on a tracing of the ganglion and cell bodies (Fig. 6B). Knowing this superposition, we can ask if the 17 detectors on which the activity of cell 90 of Figure 5 was found coincide with the image of a recognizable cell. In Figure $6 C$ we have drawn a filled rectangle at the position of the 17 diodes that had this signal. The region covered by the 17 diodes corresponds well with the very large cell at the anterior border of the ganglion. The motor function and synaptic interactions of this neuron with others in the ganglion have been studied (Levitan et al., 1970; Spira and Bennett, 1972; Spira et al., 1980; Spray et al., 1980b; Bennett et al., 1985); it has been named the $G$ (for giant) expansion motor neuron. The 5 detectors that had the signal from cell 18 


\section{CELL LOCALIZATION}

A.

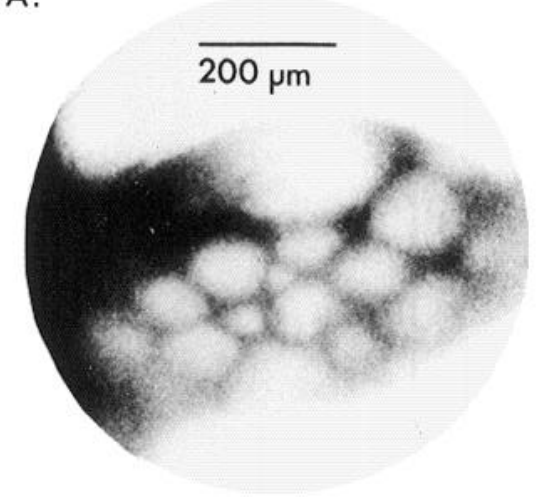

C. 90

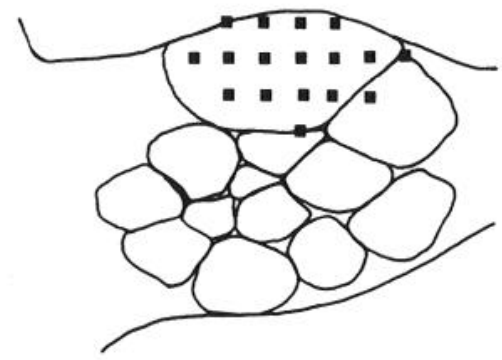

B.

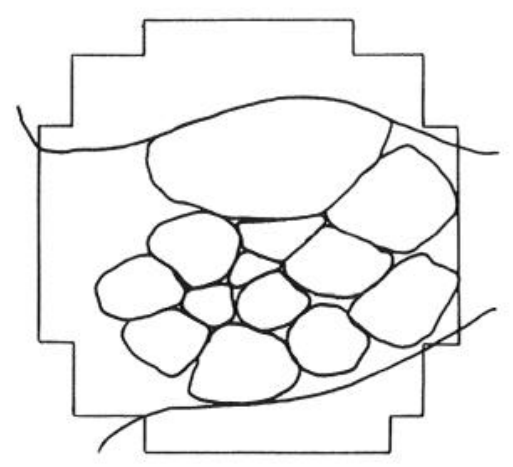

D. 18

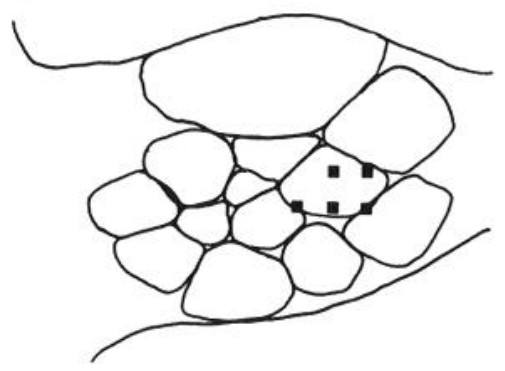

E. 39

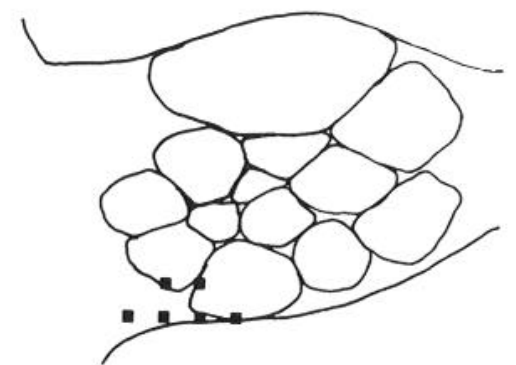

Figure 6. Photograph of the ganglion in the experiment illustrated in Figure 5; superimposition on the photograph of elements of the array on which activity of individual neurons was detected. $A$, Photograph of the ganglion, with the microscope focused at the upper (ventral) cell layer. $B$, Perimeter of the 124 elements of the array is superimposed on a tracing of the ganglion and cell bodies. $C$, A filled square is drawn at the position of each of the 17 detectors on which the signal from photodiode 90 (Fig. 5) was seen. These detectors correspond well with the position of a giant cell body. $D$, The detectors with the activity of cell 18 from Figure 5 are superimposed on the drawing. $E$, The detectors with the activity of cell 39 are superimposed. The photograph was made immediately following the optical measurement of Figure 5.

superimposed on the image of a large cell body (Fig. $6 D$ ). However, the 6 detectors that had the signal from cell 39 did not superimpose over the image of a neuron in this photograph (Fig. $6 E)$. We presume that this cell body has an image that cannot be discerned at this plane of focus. In living ganglia, anatomical identifications can be made only for those cell bodies that can be visualized. The cell bodies on the bottom side of the ganglion and those underneath the top layer on the top side cannot be visualized in vivo, although it should be possible to make a reconstruction from a stained and cleared ganglion.

\section{Reproducibility of neuron activity during repeated behaviors}

One advantage of simultaneously recording from many cells is the ability to test the reproducibility of the neuronal activity pattern that underlies a specific behavior. In 1 preparation we made 2 recordings of activity during spontaneous expansions that occurred $20 \mathrm{~min}$ apart. The raster diagrams from the 2 optical recordings are shown in Figure 7 (left). Although the spike activity appears to be similar in the 2 expansions, additional information is needed to determine if the same set of cells is participating. The positions of 6 cells from the 2 recordings are shown on the diagrams of the photodiode array on the right. These 6 neurons, the top 6 in the raster diagrams, have activity on the same detectors in both expansions. Furthermore, the shapes and sizes of their optical signals are similar in both expansions. In the middle right of the figure, the averaged action potentials for 3 of the neurons $-15,72$, and 35 -are shown for both recordings. The action potential shapes for cells 39,45 , and 75 were also similar in both recordings. While 6 of the neurons that are active during the 2 expansions appear to be identical, the other active neurons ( 2 in the first expansion and 3 in the second expansion) were not. Furthermore, although the spike activity of 4 of the identical neurons was similar in the 2 expansions, for cells 75 and 45 , there were large differences in the number of action potentials.

In 7 different preparations we measured activity in 10-22 neurons during spontaneous expansions. In those preparations, measurements during nerve stimulation indicated that action potentials in 100 or more neurons could have been detected (see below). In each preparation a giant neuron, whose activity fell on 12 or more detectors, was active during the expansion. Since this giant cell was always located in the anterior portion of the ganglion, it is likely to be the $\mathrm{G}$ motor neuron. In each case this neuron was active only just before and during the increase in pharyngeal volume, a result that is consistent with the facts that action potentials in the $\mathrm{G}$ motor neuron leads to expansion and the $\mathrm{G}$ motor neuron innervates the entire pharyngeal muscle (Spira et al., 1980). Thus, it appears that most spontaneous expansions involve activity in the $\mathrm{G}$ motor neuron. However, the numbers of neurons involved in apparently sim- 
FIRST

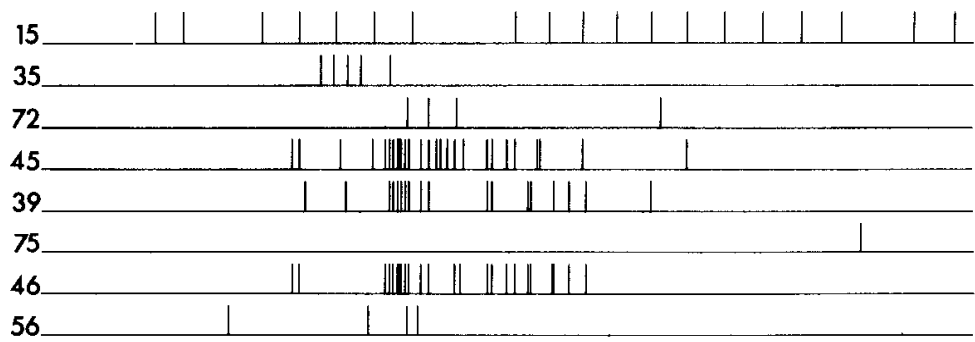

MOVEMENT

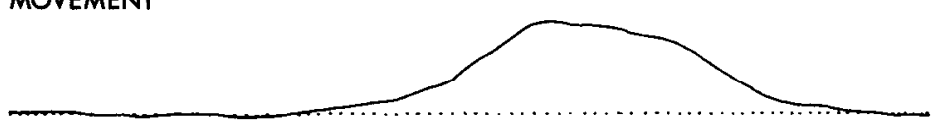

SECOND

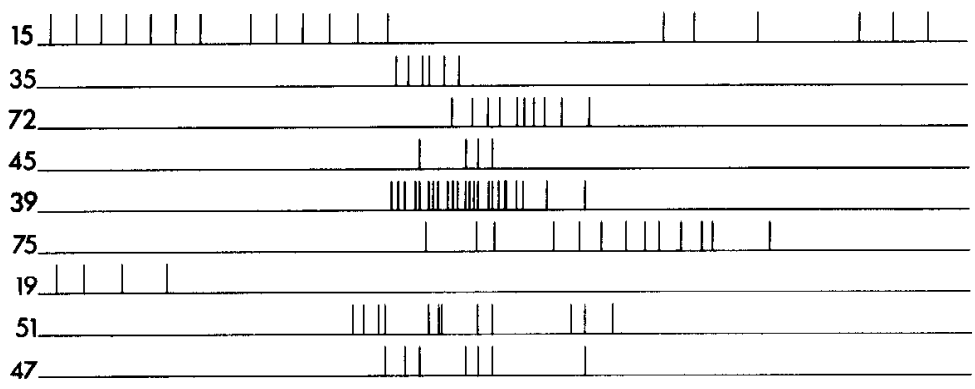

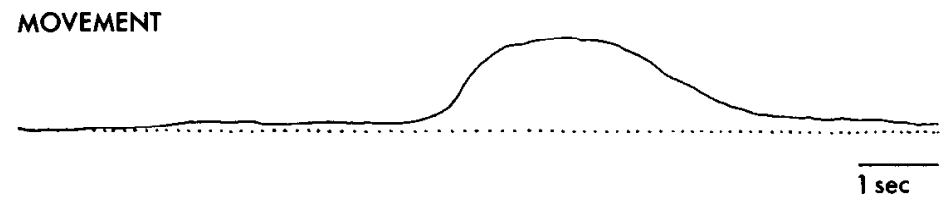

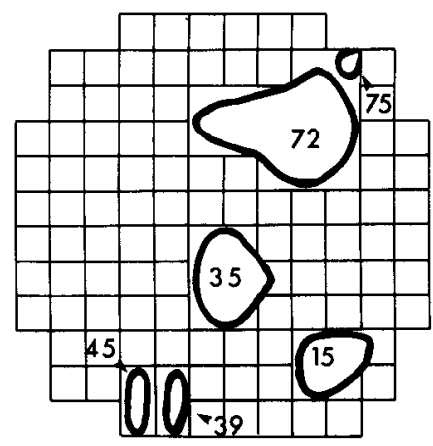
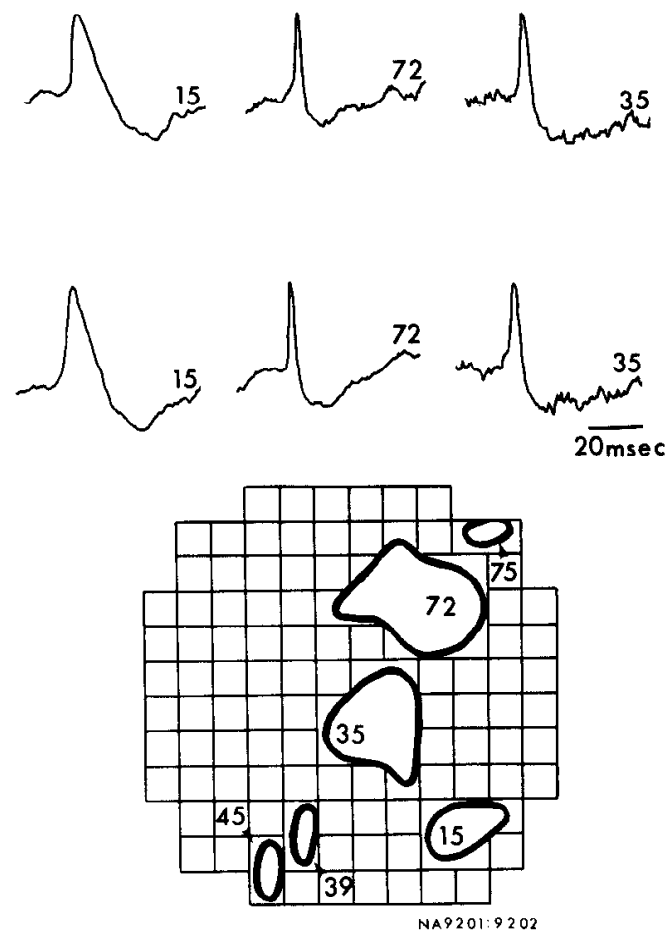

Figure 7. Left, Raster diagrams from optical recordings from 2 spontaneous expansions in the same preparation. Right, The locations of 6 of the cells on the array are shown for both expansions. The time course of the action potentials of 3 of these cells is also shown for both expansions. Digital filtering was not used for these recordings. From the locations, time coursc, signal sizc, and firing patterns, it seems highly likely that these 6 neurons are active in both expansions. There are slight differences in position for 4 of the neurons we claim are identical $(35,39,72$, and 75$)$. Examination of the averaged traces indicates that the differences occur on detectors where the signal is very close to the $50 \%$ criterion and, thus, that the differences result from noise in the averaged records. In this preparation, activity in only 50 neurons was detected when the nerves were cut and stimulated. Thus, it is likely that substantially more neurons than those indicated were actually active during the expansions.

ilar spontaneous expansions can be quite different from animal to animal.

\section{Activity during feeding}

Actual feeding was observed in several preparations. The results of an optical recording made during feeding are illustrated in Figure 8 . The top 24 traces illustrate the spike activity of 22 neurons. At the bottom of the figure are photographs made from the simultaneous video-tape recording. The timing of the photographs are indicated by the dots on the movement detector baseline. The food, a piece of Bulla, one of Navanax's natural prey species, is outside the mouth in frames $1-3$ and is ingested between frames 3 and 4 . The Bulla remained in the pharynx for several minutes until it was pulled out with the fishing rod. Both the movement trace and the action potential activity appear to be more complex during feeding than during spontaneous expansions. Several of the neurons that are active after the main expansion have a firing pattern composed of several bursts. This may be activity in circumferential motor neurons responsible for peristaltic movements of the pharynx (Bennett et al., 1985). Although the data in Figure 8 do not indicate any neurons whose activity is found on more than 8 detectors, it is possible that cell number 121 is the $\mathrm{G}$ motor neuron. These signals are from the anterior part of the ganglion but were, unfortunately, at the edge of the array, so we do not know the total size of the cell body. The results in Figure 8 indicate substantially more simultaneous firing of neurons during the feeding than was seen during the spontaneous expansions. During this feeding, cell 33 sometimes fired simultaneously with 21 and 39 , cell 48 fired with 49 , and cell 95 fired with 96 and 107 .

In 4 preparations we made optical measurements during spontaneous expansions and during feeding. On average there were $40 \%$ more cells active during feeding than during the spontaneous expansions. 


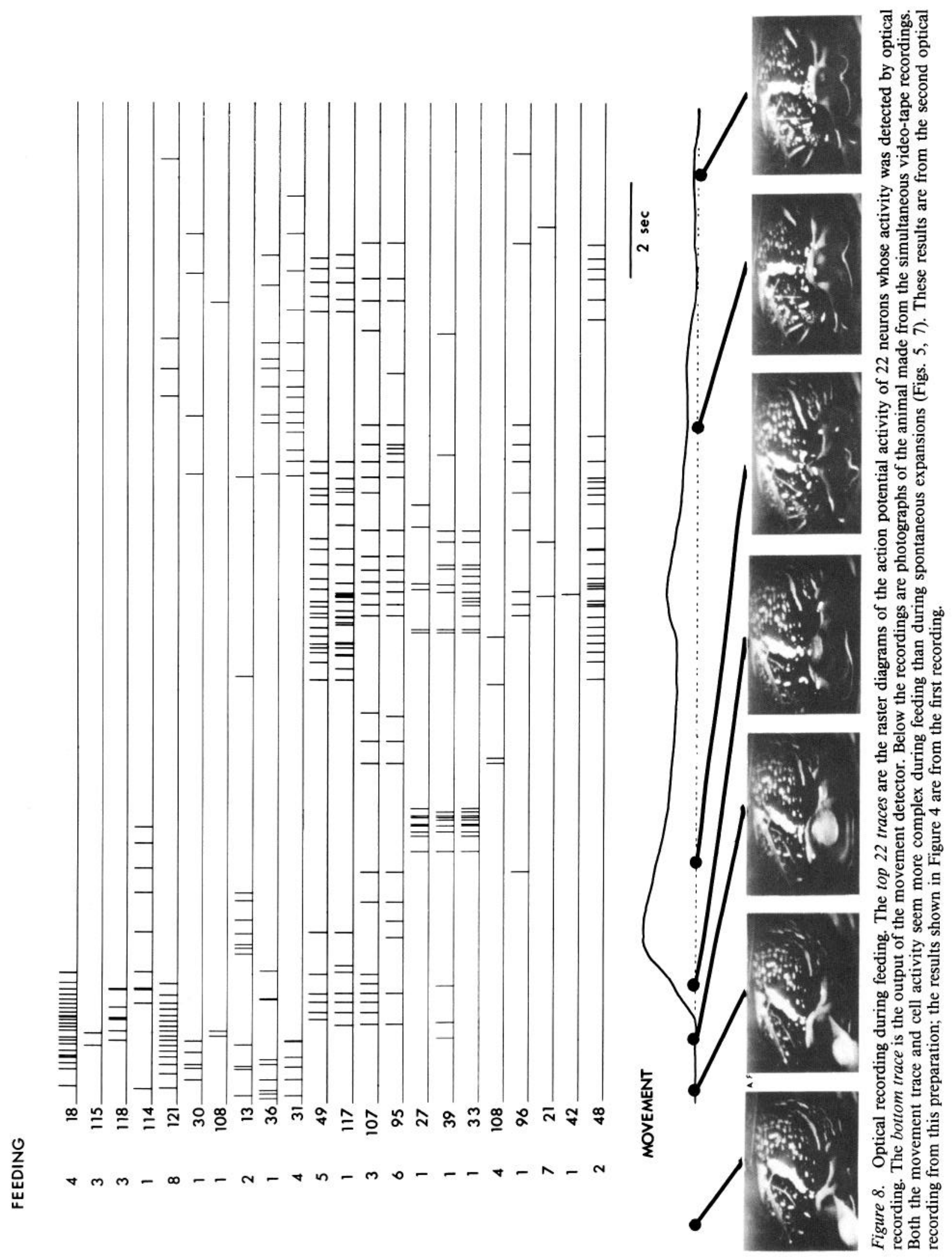


Table 1. Completeness of the optical recordings

\begin{tabular}{llll}
$\begin{array}{l}\text { Prepa- } \\
\text { ration }\end{array}$ & $\begin{array}{l}\text { Number of neurons } \\
\text { whose activity was } \\
\text { detected optically }\end{array}$ & $\begin{array}{l}\text { Cell bodies } \\
\text { in the } \\
\text { ganglion }\end{array}$ & Percent \\
\hline 89 & 140 & 183 & 77 \\
93 & 128 & 162 & 79 \\
95 & 112 & 203 & 55 \\
\hline
\end{tabular}

\section{Averaging}

The spike-triggered averaging illustrated in Figure 4 also allows one to determine if the action potentials in other neurons are time locked to the spikes in the ncuron used for triggering. In the recording shown in Figure $4 A$ there is a signal from a second cell at the upper left (e.g., detector number 115 , filled square) whose action potential peak is delayed by $7 \mathrm{msec}$ compared to the spike in the cell (number 18) used to trigger the averaging. The timing of the 2 signals is indicated in the expanded traces in the inset at the right (Fig. $4 B$ ). The signal from detector 18 is shown at the top, and the signal from detector 115 is shown at the bottom. When the original recordings were examined we found that in 8 instances the firing of cell 18 was followed with a nearly constant latency by firing of cell 115 . Cell 115 generated 9 other spikes that were not so tightly time linked to activity in cell 18 , and cell 18 made 17 additional action potentials that did not drive activity in 115 . Spira et al. (1980) have demonstrated this kind of interaction between $M$ and $G$ cells in isolated ganglia.

\section{How complete are the recordings?}

Using methods developed by Macagno (Macagno, 1980; Boyle et al., 1983), we counted an average of $200 \pm 10$ (SEM) cell bodies in 16 buccal ganglia. Thus, our recordings during spontaneous expansions and feeding were detecting activity in only $5-15 \%$ of the neurons in the ganglion. This could indicate that only a small fraction of the available population is active during the behaviors we examined. On the other hand, this result could mean that our recordings were very incomplete; that either the apparatus was not sensitive enough to detect more activity, or that the dye binding was selective and only a small fraction of the cells were effectively stained. To provide an estimate of the minimum number of cells whose activity could be detected, we carried out stimulation experiments on several preparations. All the nerves leading to the buccal ganglion were cut, and we used 6 suction electrodes to stimulate 6 of the nerves sequentially during a $17 \mathrm{sec}$ optical recording. For each electrode 3 stimulus strengths were used. The recordings shown in Figure 3 are from such a stimulation experiment. Using the type of analysis described for Figure 3, we counted the number of neurons whose activity could be detected optically. In 3 of these preparations we subsequently stained the ganglion with methylene blue and counted the number of cell bodies using the CARTOS system (Macagno, 1980). A comparison of the number of cells whose action potential activity could be detected with the number of cell bodies present in the 3 ganglia is given in Table 1 . On average we detected activity in slightly more than $70 \%$ of the neurons present in the ganglion. In 2 preparations for which each of the authors determined the number of neurons whose activity could be detected optically, the SEM for each preparation was $8 \%$ of the mean. In 2 preparations for which each author indepen- dently counted the number of cell bodies present in a ganglion, the SEM averaged $2 \%$ of the mean. Table 1 reports the means of the individual determinations.

\section{Discussion}

Although we think that the anatomical counts of cell bodies in the ganglia are relatively reliable, there are 3 factors that could lead to errors in counting the number of neurons whose activity was detected optically. These errors will affect the analysis of stimulation experiments more than measurements made during behaviors. The first kind of error results from masking of signals when many neurons are simultaneously active. The ventral surface of the ganglion is completely covered by a few large neurons. If a stimulus activates all those neurons, then every detector recciving light from the ganglion will have an action potential signal from those large cells. If additional neurons are active at that time (and their activity occurs only at that time), their activity will not be discernible. (A representative example of synchronous spike activity on every detector is the signal shown at the fourth $S$ in Fig. 3.) The second kind of error results from the small signal-to-noise ratios obtained for small neurons. When 2 small neurons are imaged onto a single detector and both are active, it is difficult to know that the cells were different with the present signal-to-noise ratio. Both of these factors lead to an underestimate of the number of active neurons. A third factor could lead to overestimation. If 2 cells are electrically coupled and sometimes fire simultaneously and sometimes independently, there will be 3 spatial distributions of signals, which can be interpreted as 3 neurons, the 2 independently firing cells and the third (larger) unit, which is actually the simultaneous firing of the 2 cells. By carefully examining firing patterns and waveforms, we think that we have avoided this kind of error.

Our estimate that the recordings were $70 \%$ complete would also be low if the stimulation procedure did not activate all of the neurons; for example, neurons might be inhibited rather than excited by nerve stimulation. The circumferential motor neurons in Navanax are inhibited by pharyngeal nerve stimulation (Bennett et al., 1986), and in Aplysia, R15, L8, L10, and L11 are inhibited by connective or nerve stimulation (Frazier et al., 1967). Thus, there are a number of factors that could cause our count to underestimate the actual completeness of the recordings.

Since the apparatus was able to detect activity in a substantial fraction of the neurons in the ganglion, the fact that less than $20 \%$ of the neurons were active during feeding did not result from inability to detect activity in more neurons. It is possible that the trauma of dissection and the restrictions of the animal's movement may have reduced the number of active neurons. In addition, the food piece was small and many mechanosensory cells (Spray et al., 1980a) may not have been activated. In Aplysia, a dissection even less extensive than the one used here led to a dramatic reduction in the duration of siphon- and gillwithdrawal reflexes and to a reduction in the number of interneurons active in the reflexes (Kanz et al., 1979). Similarly, the feeding behavior of our dissected preparations was less vigorous than that exhibited by intact animals. Not every dissected animal would feed, and the feeding movements of dissected preparations were somewhat slower than of intact animals.

The signal-to-noise ratios in our experiments were probably not large enough to detect activity in the smallest neurons. The signal-to-noise ratio is expected to decrease linearly with cell diameter if the size of the photodetector is equal to the size of 
the cell's image or even more rapidly if the detector is larger than the image of the cell. In the 3 ganglia used for the experiments reported in Table 1 , the median cell body diameter was $36 \mu \mathrm{m}$. With the $32 \times$ objective the image of such a cell would be similar to the size of an individual photodiode. However, $6 \%$ of the cells were smaller than $12 \mu \mathrm{m}$, and $11 \%$ were between 12 and $18 \mu \mathrm{m}$. Signals from such cells would probably be too small to detect. In fact, the preparation in Table 1 with the lowest percentage of neurons detected also had the smallest cell bodies.

\section{Light scattering}

The results shown in Figure 2 indicate that, with a buccal ganglion in the light path, the intensity reaching the central detector is $\mathbf{3}$ times greater than that reaching the $\mathbf{4}$ abutting detectors. Therefore, using $50 \%$ as the cut-off for estimating the diameter should give reasonable results. Thus, from the point of view of estimating cell size, light scattering probably does not cause large errors.

Light scattering causes a $90 \%$ reduction in the incident intensity reaching a detector that would, in a transparent preparation, receive all of the light from a point in the ganglion. Thus, scattering will reduce the signal-to-noise ratio by at least a factor of 3. [The present measurements of the percentage transmission are not directly comparable to those made by Boyle et al. (1983), who reported the percentage transmission from a number of species of opisthobranch molluscs. In contrast to the $35 \mu \mathrm{m}$ spot used for Figure 2, Boyle et al. (1983) illuminated the whole ganglion. When the whole ganglion is illuminated, the incident light intensity, $I_{0}$, remains the same, but the intensity reaching any detector, $I$, will be increased by light scattered into the central detector from surrounding cells. Thus, using the percentage transmissions given by Boyle et al. (1983) will lead to an underestimate of the degradation in signal-to-noise ratio due to scattering.]

Even though scattering appears to have substantially reduced the signal-to-noise ratio in our experiments, we were still able to record activity in more than $70 \%$ of the neurons present in buccal ganglia. In suspensions of erythrocytes, light scattering can be greatly reduced by increasing the refractive index of the solution until it matches the refractive index of the erythrocyte cytoplasm. Similarly, it might be possible to reduce scattering in molluscan ganglia. If not, then the best signal-to-noise ratios will be obtained using ganglia from animals such as Melibe and Aeolidia, which have relatively transparent ganglia (Boyle et al., 1983).

\section{Cell identification}

The results presented in Figure 6 showed that the positions of detectors with spike activity could be used to provide visual identification of the cell body in cases where the cell body could be visualized. For neurons that cannot be localized visually (cells not in the outside layer on the upper surface of the ganglion), then only the position in the object plane can be determined from an optical recording made at a single plane of focus. Measurements taken at several planes of focus (Salzberg et al., 1977) or simultaneous optical measurements from orthogonal directions would allow a 3-dimensional localization of the active cell bodies. To provide a rough functional identification of the active neurons into sensory, interneuron, and motor groups, we hope to combine optical recording with extracellular electrode measurements from the nerves and connectives.
Although the signal-to-noise ratio in our experiments was not large enough to allow monitoring of synaptic potentials, it is clear from averaged records (Fig. 4) that this capability is not far off. The possibility of larger signals from improved apparatus or better dyes has been discussed elsewhere (Waggoner and Grinvald, 1977; Salzberg, 1983; Grinvald, 1985; Cohen and Lesher, 1986).

The ability to monitor most of the action potential activity in simpler opisthobranch ganglia may be useful in several situations. In exploratory experiments it provides a quick method of discovering the neurons involved in particular behaviors or in particular neuronal circuits. In systems that have been studied extensively with microelectrodes, optical measurements may provide a powerful test of models that have been proposed to explain the observed behaviors. Optical measurements made before and after eliminating individual neurons from the circuit would provide important information about the role of those neurons.

\section{References}

Bennett, M. V. L., M. B. Zimering, M. E. Spira, and D. C. Spray (1985) Interaction of electrical and chemical synapses. In Gap Junctions, M. V. L. Bennett and D. C. Spray, eds., pp. 355-366, Cold Spring Harbor Laboratory, Cold Spring Harbor, NY.

Boyle, M. B., and L. B. Cohen (1980) Birefringence signals that monitor membrane potential in cell bodies of molluscan neurons. Fed. Proc. 39: 2130.

Boyle, M., L. B. Cohen, E. R. Macagno, and H. S. Orbach (1983) The number and size of neurons in the CNS of gastropod molluscs and their suitability for optical recording of activity. Brain Res. 266: 305317.

Cohen, L. B., and S. Lesher (1986) Optical monitoring of membrane potential: Multi-site light measurements. In Optical Methods in Cell Physiology, P. De Weer and B. M. Salzberg, eds., pp. 71-99, Wiley, Ncw York.

Cohen, L. B., and B. M. Salzberg (1978) Optical measurement of membrane potential. Rev. Physiol. Biochem. Pharmacol. 83: 35-88.

Frazier, W. T., E. R. Kandel, I. Kupfermann, R. Waziri, and R. E. Coggeshall (1967) Morphological and functional properties of identified neurons in the abdominal ganglion of Aplysia californica. J. Neurophys. 30: 1288-1351.

Grinvald, A. (1985) Real-time optical mapping of neuronal activity: From growth cones to the intact mammalian brain. Annu. Rev. Neurosci. 8: 263-305.

Grinvald, A., R. Hildesheim, R. Gupta, and L. B. Cohen (1980) Better fluorescent probes for optical measurement of changes in membrane potential. Biol. Bull. 159: 484.

Grinvald, A., L. B. Cohen, S. Lesher, and M. B. Boyle (1981) Simultaneous optical monitoring of activity of many neurons in invertebrate ganglia using a 124 element photodiode array. J. Neurophysiol. 45 : 829-840.

Grinvald, A., R. Hildesheim, I. C. Farber, and L. Anglister (1982) Improved fluorescent probes for the measurement of rapid changes in membrane potential. Biophys. J. 39: 301-308.

Kanz, K. E., L. B. Eberly, J. S. Cobbs, and H. M. Pinsker (1979) Neuronal correlates of siphon withdrawal in freely-behaving Aplysia. J. Neurophys. 42: 1538-1556.

Lektin, A. and M. Osmol (1986) Self-replication of a channel-forming protein in vitro. Biophys. J. 49: 414a.

Leonard, J. L., and K. Lukowiak (1984) An ethogram of the sea slug, Navanax inermis (Gastropoda, Opisthobranchia). Z. Tierpsychol. 65 : 327-345.

Levitan, H., L. Tauc, and J. P. Segundo (1970) Electrical transmission among neurons in the buccal ganglion of a mollusc, Navanax inermis. J. Gen. Physiol. 55: 484-496.

London, J. A., D. Zečević, and L. B. Cohen (1984) Optical monitoring of activity from buccal ganglia during pharyngeal expansion (feeding) in a minimally dissected Navanax. Soc. Neurosci. Abstr. 10:508.

London, J. A., D. Zečević, and L. B. Cohen (1985) Optical measurements, using absorption, of activity from buccal ganglia during spon- 
taneous pharyngeal expansion and during feeding. Neurosci. Lett. 22: 371.

Macagno, E. (1980) Number and distribution of neurons in leech segmental ganglia. J. Comp. Neurol. 190: 283-302.

Murray, M. J., and E. R. Lewis (1974) Sensory control of prey capture in Navanax inermis. Veliger 17: 156-158.

Orbach, H. S., and L. B. Cohen (1983) Optical monitoring of activity from many areas of the in vivo and in vitro salamander olfactory bulb: A new method for studying functional organization in the vertebrate central nervous system. J. Neurosci. 3: 2251-2262.

Paine, R. T. (1963) Food recognition and predation on opisthobranchs by Navanax inermis (Gastropoda: Opisthobranchia). Veliger 6: 1-9.

Piller, H. (1977) Microscope Photometry, Springer-Verlag, Berlin.

Pooler, J. (1972) Photodynamic alteration of sodium currents in lobster axons. J. Gen. Physiol. 60: 367.

Ross, W. N., and V. Krauthamer (1984) Optical measurements of potential changes in axons and processes of neurons of a barnacle ganglion. J. Neurosci. 4: 659-672.

Ross, W. N., and L. F. Reichardt (1979) Species-specific effects on the optical signals of voltage-sensitive dyes. J. Membr. Biol. 48: 343356.

Ross, W. N., B. M. Salzberg, L. B. Cohen, H. V. Davila, A. S. Waggoner, and C. H. Wang (1977) Changes in absorption, fluorescence, dichroism and birefringence in stained giant axons: Optical measurement of membrane potential. J. Membr. Biol. 33: 141-183.

Salzberg, B. M. (1983) Optical recording of electrical activity in neurons using molecular probes. In Current Methods in Cellular Neurobiology, J. L. Barker and J. F. McKelvey, eds., pp. 139-187, Wiley, New York.

Salzberg, B. M., H. V. Davila, and L. B. Cohen (1973) Optical recording of impulses in individual neurons of an invertebrate central nervous system. Nature 246: 508-509.

Salzberg, B. M., A. Grinvald, L. B. Cohen, H. V. Davila, and W. N.
Ross (1977) Optical recording of neuronal activity in an invertebrate central nervous system: Simultaneous monitoring of several neurons. J. Neurophysiol. 40: 1281-1291.

Selverston, A. I. (1980) Are central pattern generators understandable? Behav. Brain Sci. 3: 535-571.

Spira, M. E., and M. V. L. Bennett (1972) Synaptic control of electrotonic coupling between neurons. Brain Res. 37: 294-300.

Spira, M. E., D. C. Spray, and M. V. L. Bennett (1980) Synaptic organization of expansion motorneurons of Navanax inermis. Brain Res. 195: 241-269.

Spray, D. C., M. E. Spira, and M. V. L. Bennett (1980a) Peripheral fields and branching patterns of buccal mechanosensitive neurons in the opisthobranch mollusc, Navanax inermis. Brain Res. 182: 253270.

Spray, D. C., M. E. Spira, and M. V. L. Bennett (1980b) Synaptic connections of buccal mechanosensory neurons in the opisthobranch mollusc, Navanax inermis. Brain Res. 182: 271-286.

Susswein, A. J., Y. Achituv, M. S. Cappell, D. C. Spray, and M. V. L. Bennett (1984) Pharyngeal movements during feeding sequences in Navanax inermis: A cinematographic analysis. J. Comp. Physiol. A. 155: 209-218.

Waggoner, A. S. (1979) Dye indicators of membrane potential. Annu. Rev. Biophys. Bioeng. 8: 47-68.

Waggoner, A. S., and A. Grinvald (1977) Mechanisms of rapid optical changes of potential sensitive dyes. Ann. NY Acad. Sci. 303: $217-$ 241.

Woollacott, M. (1974) Patterned neural activity associated with prey capture in Navanax (Gastropoda, Aplysiacea). J. Comp. Physiol. 94: 69-84.

Zečević, D., J. A. London, and L. B. Cohen (1985) Simultaneous monitoring of activity of many neurons in the buccal ganglia of $\mathrm{Na}$ vanax during feeding: A demonstration. J. Gen. Physiol. 86: 19a. 